\section{CARE OF THE DYING*}

BY

\section{IAN GRANT, M.B., Ch.B. General Practitioner, Glasgow}

After more than 30 years in general practice it still amazes me to see how few patients are aware that they are dying, and, of the few who are so aware, how little they fear the approach of death. William Hunter, shortly before his death, rose from his sick-bed to deliver a lecture on the "operations of surgery." By the end of the lecture his strength was so exhausted that he fainted away, and after he recovered consciousness he whispered to a friend, "If I had strength to hold a pen, I would write how easy and pleasant a thing it is to die." The great Sir William Osler on his deathbed said, "I have been too far across the river to go back and have it all over again."

\section{Role of the G.P.}

When care is no longer possible it is the duty of the practitioner to bring contentment and comfort to his patients and to try to lighten the burden of their afflictions. But, in my view, this does not mean necessarily that he should seek merely to prolong life. There are times when I have less and less sympathy with the superhuman efforts merely to extend life in old age. The complete curtailment of activities, skilled nursing, and the assiduous care of the doctor are apt, all too frequently, to carry the aged patient tottering past the danger point and then leave him a helpless wreck of humanity.

There are, of course, special cases. I can recall a very wealthy man who had gifted most of his fortune to his family and who for the last six months of his life was gravely ill with congestive heart failure. If he died before a certain date very large sums were payable in death duties. Despite his great discomfort, I never knew a man who clung so tenaciously to life helped by the most skilled and tender nursing and assisted with all the advantages of modern pharmacy, but once the appointed date was attained he quickly gave up the struggle, and a few days later peacefully and contentedly passed into the unknown.

The philosophy of R. L. Stevenson merits much consideration. "We do not, properly speaking, love life but rather living," and again, "Does not life go down with better grace foaming in full body over a precipice than miserably struggling to an end in sandy deltas ?" It is our duty to preserve not only health and life but also the joy of living, and often as a G.P. when dealing with cases of complete senility, when both mind and body have long since served their day and generation, one wonders whether one should really "strive officiously to keep alive" by the use of antibiotics, blood transfusions, and intravenous injections of varying potency or whether we should not let nature take its course and let the weary pass quickly into eternal rest.

\section{Need for More Hospital Accommodation}

The phrase death agony is, I think, ill chosen. In the ordinary way death comes peacefully or, if not, can easily be made so by sedative and analgesic drugs. Relatives should not try to call back into activity a mind that is fitfully wandering, and, above all, there should always be present a good nurse-not necessarily a trained nurse-able and willing to give every help and comfort to the patient. More hospital accommodation should be available for the moribund. It is wrong that so many old people die in crowded and squalid surroundings often with young children crying or playing in the death chamber. It is bad for the children, who are often at a very impressionable age, and it

*Read at a Plenary Session at the Annual Meeting of the British Medical Association, Newcastle upon Tyne, 1957. adds to the difficulties of the patient ; and yet, in our overcrowded slum areas, how often are old people nursed in a crowded family living-room. Nowadays, in this welfare State, we do so much for youth. Should it not be a first priority to provide adequate hospital and nursing care for those who have served their country well and whose life is now drawing to a close? We have, to a large extent, provided adequate accommodation for births; surely it is not unreasonable to ask that the very ill and the aged should be permitted to die undisturbed by the everyday battle of family chores.

For those overtaken by grave injury, either by accident or in battle, the first need should be to ease pain, and for that purpose I advocate using morphine freely. If those sufferers must die, surely we should make their last hours as tranquil and pain-free as possible. Someone should always be at their side to take note of any message and to render them any little service. If at all possible we should never leave a gravely ill person to die alone. A return to consciousness and lucidity for a few minutes may sometimes occur, and to add loneliness to the tragedy of dying is an unkindness we should always avoid.

In general practice we find that senile patients linger on for many months, and it is impossible to forecast, even approximately, the time they may survive. Although their faculties are almost completely gone, careful nursing is essential. If possible, they should get out of bed for a little each day. Their joints must not be allowed to stiffen. So often there is a tendency for knees, hips, wrists, and elbows to become flexed and fixed, which adds greatly to the difficulties of nursing. Regular sponging and cleanliness; the watchful care of the skin to prevent bedsores, more particularly in the incontinent; small meals three to four times daily and restriction of evening fluids; and attention to bowels and bladder are all "musts" in the care of the dying. These senile patients seldom suffer pain and in their own way seem contented. Death when it comes to them is often sudden. Relatives can seldom be forewarned. The machine just runs down and they go to sleep. They seldom need drugs. For them patience and kindliness in their nurse is often all that is necessary.

\section{Telling the Patient}

In malignant disease the G.P. is often called upon to treat the inoperable case or the case where operation has failed to effect a cure. The decision on what to tell the patient invariably devolves upon the G.P., and the decision is his personal responsibility. Many patients are of such character that the doctor, if he is specifically asked, will have no great difficulty in deciding to disclose the truth, but there are many other patients, and also patients' relatives, to whom the doctor finds it very difficult to decide what he should tell. The doctor must gauge, and correctly gauge, the temperament of the patient. He must do his best to alleviate both the fears and the discomforts of the sick man, but it is unfair that he should bear this burden alone. Some relative should be told, and must accept his or her share of the burden. The doctor should never rush in with bad news to a patient, but circumstances may compel a limit to medical prevarication. Financial adjustments may be necessary-a will perhaps may require to be made, relatives from a distance may require to be summoned. Great tact must be exercised, and never should a case be pronounced completely hopeless-serious, yes, but extraordinary recoveries are on record, and it is only the foolish who are completely dogmatic.

I often think that, with experience, one gets the feel of patients and whether they want to know the full facts or not. With Pilate, we may oft-times ask, "What is truth?", and so often, at best, we can tell only part of it, for we do not know the whole.

\section{Use of Drugs}

In the treatment of malignant cases it is well to withhold morphine as long as possible, for the patient so very quickly develops tolerance to the drug, and in a few months doses 
must be increased to an amount far exceeding the pharmacopoeial dose.

The different curative and euphoric effects of morphine are sometimes astonishing. Frequently I have given a fairly large dose of morphine to a patient, and on returning next day found him physically much better and mentally much more tranquil and peaceful. A colleague had two patients with very important business interests which required, if possible, the continued presence of these men on the directorate. Both had malignant secondaries, but were able to remain at business for several months, although latterly they were each taking $14 \mathrm{gr}$. $(0.9 \mathrm{~g}$.) of morphine daily and remained at work.

Methadone, dihydrocodeine, codeine, and the barbiturates all have their uses in the less painful stages, but when the misery of the patient becomes desperate, as in advanced cancer of the tongue or secondaries in the bones, then indeed we should not spare the Waters of Lethe, and I am convinced that our first duty is to relieve pain and to induce merciful oblivion.

In the care of those dying from congestive heart failure, nursing plays a very important part. When the patient becomes waterlogged and restless, no position is comfortable for long and some little postural adjustment may be necessary every hour. An adjustable chair is a great boon, and sometimes these patients sleep more comfortably in a chair than in bed. Mersalyl and its synonyms are of much value, and aspiration of an ascites gives temporary relief, but this line of treatment should be delayed as long as possible. The abdomen again quickly fills up, and so often patients are disappointed and depressed at the recurrence of the fluid. The operation, although comparatively simple, becomes, after several aspirations, a major ordeal, and it is then again that I wonder whether we should strive officiously to keep alive. A similar problem faces us with uraemia. Should we persist with drugs which can give only temporary relief ?

In a different category is tuberculosis, which only a decade ago took heavy toll often of the most able and intelligent of our population. Thanks to modern surgery and chemotherapy, the ravages of pulmonary tuberculosis have been checked and few tuberculous patients now can be classified as "the dying."

In general practice we must include the chronic rheumatoids and those with cerebral thrombosis and cerebral haemorrhage in the category of dying, although their span of life can never be told with any degree of accuracy. They become wholly dependent on their relatives. Their mental acumen deteriorates; they eat, they sleep, their bodily functions continue, but they are a constant problem to their relatives. They require endless nursing care and attention and so often they become incontinent and appear incapable of appreciating either instruction or encouragement.

A sedative at night is helpful, but it is wrong to prescribe morphine for these patients. There is little that we, as doctors, can do beyond keeping up the morale of the relatives even more than that of the patients. But for these cases, which cause an almost unbearable strain on conscientious relatives, there should be found in our N.H.S. some type of hospitalization.

\section{Geriatric and Other Problems}

Many lonely old people still die from malnutrition and some of its associated diseases such as the anaemias and scurvy. Admittedly, they are a geriatric problem and hospitalization in some form or other is the only answer. They get into a lethargic state both mentally and physically and become too weary to care for themselves. As practitioners, we can help by frequent visits to these old people, by arranging for meals on wheels, nursing care, and the provision of a home help, but all these facilities are still inadequately supplied, and the public conscience needs awakening to the requirements of those who have served their country faithfully and well during their working years.
So often as G.P.s our problem is a dual one-to care for the dying and to care for their relatives. How often do we see devoted mothers and dutiful daughters sacrificing their health and strength in attendance on a loved one. To them we must give what help and advice we can. No one should be allowed to remain on nursing duty night and day, and during the off-duty period the relative must have an occasional change of environment. There is nothing callous or heartless in a daughter going to a cinema or dance even though a parent is gravely ill with a chronic disease. The morale of relatives must be maintained, and for that purpose some of the tranquillizers are of value both for patients and for relatives.

Let us visit our dying patient as often as we can find time, but we should never discuss a patient's progress with relatives when in the sick-room. So often a patient may appear to be unconscious, but he or she may overhear an expression of opinion which, to one who is gravely ill, may cause added distress and anxiety. Let us remember that although we may be able to do little for the patient our visit is of inestimable help to anxious relatives and we can thereby make their duties a little less burdensome.

We, as general practitioners, must remember when associating with the sick that they require kindness most of all, and that they first and foremost wish and hope to find a comprehending and sympathetic friend in their physician.

\section{WHEN IS A DOCTOR NEGLIGENT?}

\section{B.M.A. LECTURE BY MISS ROSE HEILBRON}

Miss Rose Heilbron, LL.M., Q.C., Recorder of Burnley, delivered the annual B.M.A. lecture to the St. Pancras Division on December 11. She took as her subject "The Legal Responsibilities of Doctors."

Between the years 1948 and 1953 the total sum awarded against medical practitioners for professional negligence increased to a very alarming degree, said Miss Heilbron. Since 1953, however, the number of cases against doctors had decreased, and it was now less easy to recover damages ; there had been a number of recent decisions embodying clearly expressed judicial opinion that a doctor should not be held liable for negligence merely because a mishap occurred. Nevertheless, the number of cases brought against doctors was still formidable, and it was therefore not surprising that the profession as a whole was now very conscious of its legal responsibilities and was anxious to know more about them.

\section{Three Reasons for Increased Litigation}

Three factors had contributed to the present state of affairs. The first was the introduction of the Health Service, the second the changes in the law relating to the liabilities of hospitals for the negligence of their staff, and the third the introduction of legal aid. All these changes occurred between 1946 and 1951.

It was clear that the attitude of the public towards hospitals and doctors had altered since the introduction of the Health Service. Before 1946, when hospitals were voluntary, far fewer medical actions were brought. Then there were the changes in the law itself. The law had developed so that, although for long it had been held that hospitals were not liable for the negligence of their doctors and nurses provided reasonable care had been taken in their selection, it was now clear that hospitals incurred not only a personal liability for acts of negligence causing damage-for instance, damage due to a negligent system adopted and maintained by them -but also a vicarious liability for the negligent acts of any member of their professional staff. This might even include the acts of a part-time visiting consultant, although that liability had not yet been clearly decided. This development could be traced mainly to decisions in three cases; and, although the alterations had occurred in a very short space 